\title{
A new BDA policy
}

[The new policy] starts by reaffirming that the

BDA is committed to both prevention and the promotion of oral health and also supports the principle of a publicly funded health service, available to all.
$\mathbf{T}$ he BDA's Representative Body has refined its policy on members working in the NHS and the private sector (described on page 392 in this issue). It took just over a year for the final wording to be agreed after many hours of discussion at both Representative Body and Executive Board as well as in the branches and groups. In doing this, a gap in BDA's policy has been successfully filled and we can now answer questions as to where the BDA stands on this important issue.

It must be admitted that, for the last 10 years if not more, opinion within the profession has been divided on this subject. It affects almost every one within the Association, whether they are in wholly private practice, mixed NHS/private practice or totally in the NHS, including those who work within the salaried services. Members may well ask why it is taken so long to arrive at a definitive policy.

The relationship of the BDA with the NHS has not always been easy. In the months leading up to the start of the service in July 1948, the Association, through the $B D J$, ran a vigorous campaign urging dentists members not to sign up. The arguments were then about an inevitable loss of professional freedom in joining what was seen as a nationalised service. Many of the concerns of our forebears have since been realised and many of the arguments they put forward are as relevant in the 21 st century as they were over 50 years ago.

From then on, the BDA, mainly through its central committees such as the GDSC, became closely identified with NHS dentistry in all its forms. The Association was the sole negotiator on remuneration, terms and conditions in the service. This focus changed with the new GDS contract in 1990 and the subsequent fee cut of 1992, so that an increasing number of BDA members sought their future in private practice. At the same time, however, not only were all our members in the salaried services wholly committed to the NHS, but many general dental practitioners still carried out most of their work in the GDS.

There has thus been some polarisation of opinion within the Association over the last ten years. On the one hand there are those who have moved more towards the private sector and look to the Association for support. On the other hand there are those who are fully committed to the NHS, in both salaried services and the GDS, who want the Association to continue its support for them.

The new policy thus embraces both these points of view. It starts by reaffirming that the $\mathrm{BDA}$ is committed to both prevention and the promotion of oral health and also supports the principle of a publicly funded health service, available to all. This rejects the idea of first class service available only to those who can afford it and an inferior service provided by the state. The Association also has reaffirmed its support for those members who work in the salaried services.

Turning to the GDS, the policy states quite unequivocally that ethical and professional standards are being compromised and some dentists have been driven into the private sector. Until working conditions improve significantly, the BDA cannot support the GDS as the sole source of funding for a dental practice. To address this problem the policy lays down three guiding principles. The BDA supports its members who are looking for alternative sources of funding for their practices, and will also continue to provide substantial support for those members who move into the private sector. Recognising, however, that many members will continue to work within the GDS, the BDA will redouble its efforts are over the next year to improve their terms and conditions of service.

The new policy has taken a long time to agree, but it embraces the full range of opinion within the BDA and provides us with a platform on which to develop

Michael Watson policies towards both private and NHS sectors, ultimately to improve oral health BDA Special Adviser and dental treatment for our patients. 